\title{
PERSEPSI ORANG TUA SISWA TENTANG GEOGRAFI SEBAGAI MATA PELAJARAN DI SMA DAN MA NEGERI DI KOTA SUNGAI PENUH
}

\author{
Ikhwanul Furqon $^{1}$, Ernawati ${ }^{2}$, Ratna Wilis ${ }^{2}$ \\ Program Studi Pendidikan Geografi, \\ Fakultas Ilmu Sosial, Universitas Negeri Padang \\ Email: ikhwanfurqon@gmai.com
}

\begin{abstract}
Abstrak
Penelitian ini bertujuan untuk mengetahui bagaimana persepsi orang tua siswa tentang geografi sebagai mata pelajaran di SMA dan MA Negeri di Kota Sungai Penuh. Penelitian ini merupakan penelitian deskriptif kuantitatif dengan metode survey menggunakan angket sebagai instrumen penelitian. Subjek dalam penelitian ini adalah Orang Tua Siswa di SMA dan MA Negeri di Kota Sungai Penuh yang berjumlah sebanyak 1415 orang, dan diambil sampel sebanyak 93 orang denga menggunakan teknik Slovin. Analisis data dilakukan dengan statistik deskriptif dengan persentase. Hasil penelitian menunjukkan bahwa persepsi orang tua siswa mengenai peran ilmu geografi dalam suatu profesi tergolong kurang baik dengan persentasi $38,71 \%$, persepsi orang tua siswa tentang peran mata pelajaran geografi dalam membentuk sikap peduli lingkungan tergolong baik dengan persentase $32,26 \%$, persepsi orang tua siswa tentang peran ilmu geografi dalam pemecahan masalah global tergolong cukup baik dengan persentase $49,46 \%$, dan persepsi orang tua siswa tentang pembelajaran geografi di SMA/MA tergolong cukup baik dengan persentase $33,33 \%$.
\end{abstract}

Kata Kunci: Persepsi, Mata Pelajaran Geografi, Orang Tua Siswa

\begin{abstract}
Aims of this sutdy is to understand how Parents peerception of geography as a subject in state SMA and MA in Sungai Penuh City. This research is descriptive quantitative with survey method, using questionnaire as research instrument. Subject of this research is Parents of Students in State SMA and MA in Sungai Penuh City which is 1415 parents, and sample about 93 parents. Data analysis using descriptive statistic with persentage. Result of this research shows that parents perception about role of geography knowledge in a proffesion is not good with persentage $38,71 \%$, parents perception about role of geography subject in attitude thoward environmental care is good with persentage $32,26 \%$, parents perception about role of geography knowledge about global issues is quite good with persentage 49,46\%, and parents perception about geography study in SMA/MA is quite good with persentage $33,33 \%$.
\end{abstract}

Key Word: Perception, Geography Subject, Students Parents.

\footnotetext{
${ }^{1}$ Mahasiswa Program Studi Pendidikan Geografi untuk Wisuda September 2017

${ }^{2}$ Dosen Jurusan Geografi Fakultas Ilmu Sosial Universitas Negeri Padang
} 


\section{PENDAHULUAN}

Geografi adalah ilmu yang mempelajari persamaan, dan perbedaan fenomena geosfer dengan sudut pandang kewilayahan, dan kelingkungan dalam konteks keruangan (Seminar dan lokakarya Ikatan Geograf Indonesia, 1988). Geografi menawarkan komponen pengetahuan yang berguna dalam kehidupan sehari-hari. Pelajarannya unik dalam memberikan informasi yang diperlukan untuk orientasi di bidang sosial ekonomi dan menghubungkan antara masyarakat dengan lingkungan.

Di Indonesia, mata pelajaran geografi mulai diajarkan sebagai ilmu bumi pada Kurikulum Rentcana Pelajaran tahun 1947. Seiring dengan perkembangan kurikulum di Indonesia, geografi pun menjadi mata pelajaran sendiri di Sekolah Menengah Pertama dan Sekolah Menengah Atas. Namun dengan keluarnya Permendikbud No. 58 Th. 2014, Tentang Kurikulum 2013 SMP/MTs, geografi diintegrasikan dengan mata pelajaran rumpun ilmu sosial lainnya pada Sekolah Menengah Pertama dalam mata pelajaran Ilmu Pengetahuan Sosial. Kemudian di Sekolah Menengah Atas, geografi tetap ada dan diperluas lagi pengajarannya dengan adanya peminatan geografi.

Menurut Maryani dalam Ali (2006) di persekolahan ilmu geografi seringkali dianggap tidak menarik untuk dipelajari. Hal ini disebabkan oleh faktor (1) pelajaran geografi seringkali terjebak pada aspek kognitif tingkat rendah yaitu menghafal nama-nama tempat, sungai dan gunung, atau sejumlah fakta lainnya; (2) ilmu geografi seringkali dikaitkan ilmu yang hanya pembuatan peta; (3) geografi hanya menggambarkan tentang perjalananperjalanan manusia di permukaan bumi; (4) proses pembelajaran ilmu geografi cenderung bersifat verbal; kurang melibatkan fakta-fakta aktual, tidak menggunakan media kongkrit dan teknologi mutakhir; (5) kurang aplikabel dalam memecahkan masalah-masalah yang berkembang saat ini.

Pemahaman orang tua siswa akan mata pelajaran geografi berperan dalam mengarahkan jurusan anaknya di Sekolah Menengah Atas. Karena hanya jurusan IPS di SMA/MA yang mempelajari geografi, ditambah lagi orang tua juga harus tahu haruskah anaknya yang berjurusan IPA untuk mengambil peminatan geografi atau tidak. Maka dituntut pengetahuan akan geografi sebagai mata pelajaran oleh orang tua siswa SMA/MA, karena orang tua berperan dalam pemaham anak dalam pemilihan jurusan (Rini, 2014). Selanjutnya, siswa yang mempelajari geografi akan mempengaruhi pemilihan jurusan di perkuliahannya yang berdampak pada profesinya.

Selain dari segi pemahaman orang tua siswa. Pemilihan jurusan oleh siswa di sekolah juga dipengaruhi oleh motivasi siswa dan fasilitas yang tersedia di sekolah maupun di rumah siswa. Motivasi siswa ingin memilih jurusan akan berpengaruh kepada pilihan siswa nantinya karena akan terkait dengan jurusan yang akan dipilih pada perguruan tinggi. Fasilitas sekolah yang tersedia untuk suatu jurusan akan mempengaruhi pilihan siswa. Jika fasilitasnya lengkap, maka kecenderungan siswa untuk memilih jurusan tersebut akan semakin tinggi. Selanjutnya fasilitas yang disediakan sendiri oleh orang tua siswa, seperti 
buku paket yang menunjang minat siswa untuk belajar.

Masalah di atas tentang kurangnya pengetahuan orang tua tentang mata pelajaran geografi dan kurang bermaknanya pembelajaran geografi terjadi di Kota Sungai Penuh. Sedangkan idealnya, orang tua sebagai orang terdekat anak harus memahami dan berkomunikasi dengan anaknya, salah satunya dalam hal terkait mata pelajaran yang dipelajarinya di sekolah. Maka dari itu peneliti ingin meneliti lebih lanjut permasalahn tersebut melalui penelitian ini di Kota Sungai Penuh, Provinsi Jambi. Penelitian dilakukan di Kota Sungai Penuh untuk melihat persepsi orang tua siswa tentang mata pelajaran geografi di SMA/MA. Pentingnya penelitian ini karena pemahaman akan mata pelajaran geografi masyarakat terutama orang tua haruslah baik agar dapat mengarahkan anaknya untuk mempelajari geografi dengan lebih baik. Maka dari itu, diteliti terlebih dahulu persepsi orang tua siswa tentang geografi sebagai mata pelajaran di SMA/MA.

Tujuan dari penelitian ini adalah untuk dapat mengetahui persepsi orang tua siswa tentang geografi sebagai mata pelajaran. Maka dari itu, dirumuskan beberapa indikator untuk dapat mengetahuinya:

1. Mengetahui persepsi orang tua siswa tentang peran ilmu geografi dalam suatu profesi.

2. Mengetahui persepsi orang tua siswa tentang peran mata pelajaran geografi dalam membentuk sikap peduli lingkungan siswa SMA/MA.

3. Mengetahui persepsi orang tua siswa tentang kegunaan ilmu geografi dalam memecahkan masalah global.
4. Mengetahui persepsi orang tua tentang pembelajaran geografi di SMA/MA.

Menurut Walgito (2003) persepsi merupakan suatu proses yang didahului oleh proses penginderaan, yaitu merupakan proses diterimanya stimulus oleh individu melalui alat indera atau juga disebut proses sensoris.

Menurut David Krech dan Richard. S. Critchfield yang dikutip oleh Setiyana (2013), menyebutkan persepsi dipengaruhi oleh faktor fungsional dan faktor struktural.

1. Faktor fungsional atau faktor personal adalah faktor-faktor yang berkaitan dengan pemahaman individu terhadap dampak dari stimuli yang dihasilkan.

2. Faktor struktural atau faktor situasional adalah faktor eksternal yang mempengaruhi pemahaman individu terhadap stimuli yang ada. menurut Setiyana (2013) faktor struktural dapat dilihat dari kurikulum dan pelaksanaan mata pelajaran.

\section{Mata Pelajaran Geografi}

Geografi sebagai ilmu yang mempelajari hubungan kausal berbagai gejala dan peristiwa di permukaan bumi, merupakan mata pelajaran penting yang dapat memberikan sumbangsih dalam mengatasi permasalahan dunia. Di sejumlah negara, geografi telah ditempatkan sebagai mata pelajaran inti dan telah banyak membantu proses pengambilan keputusandalam pembangunan. Di Indonesia, materi geografi diberikan pada jenjang pendidikan dasar sebagai bagian integral dari Ilmu Pengetahuan Sosial (IPS) dan diberikan pada jenjang pendidikan menengah sebagai mata pelajaran tersendiri. Untuk mencapai kompetensi bidang geografi pada 
Abad XXI, Kurikulum 2013 telah mempertimbangkan berbagai tuntutan, masalah, dan harapan bangsa Indonesia pada khususnya dan harapan dunia pada umumnya sebagaimana yang dirumuskan pada Framework for 21st Century Learning (Kementerian Pendidikan dan Kebudayaan, 2016).

\section{Orang Tua}

Mengenai pengertian orang tua dalam kamus besar bahasa Indonesia disebutkan Orang tua artinya ayah dan ibu. (Depdiknas, 2008). Hubungan orang tua dan anak dalam keluarga terjalin melalui interaksi komunikasi yang mereka lakukan sehari-hari. Setiap kegiatan orang tua dan anak dapat menentukan interksi komunikasi di antara keduanya. Interaksi orang tua dan anak dikarenakan oleh adanya peran orang tua dalam keluarga terhadap anaknya. Dalam kegiatan komunikasi antara orangtua dan anak juga melibatkan proses pengambilan keputusan. Menurut Noller dkk. (1993), pengambilan keputusan merupakan kegiatan sentral dalam sebuah keluarga yang dapat dilakukan melalui dialog dan yang langsung diputuskan.

\section{METODE PENELITIAN Pengumpulan Data}

Untuk dapat mengetahui persepsi orang tua siswa tentang geografi sebagai mata pelajaran di SMA dan MA Negeri di Kota Sungai Penuh, peneliti menggunakan jenis penelitian deskriptif kuantitatif dengan metode survey. Data sekunder diperlukan terlebih dahulu dengan meminta data di sekolah yang bersangkutan. Selanjutnya data primer dikumpulkan sendiri oleh peneliti dengan menemui orang tua siswa dan memberikan angket kepada siswa untuk diserahkan kepada orang tua siwa. Data primer dikumpulkan dengan menggunkan angket sebagai instrumen penelitian.

\section{Populasi dan Sampel Penelitian}

Subjek penelitian ini yaitu orang tua siswa SMA/MA Negeri di Kota Sungai Penuh. Sampel alam penelitian diambil dengan teknik purposif random sampling (Usman, dkk. 2008). Jumlah sampel yang harus diambil dalam penelitian menggunakan teknik penentuan sampel oleh Slovin (Sujarweni, 2014). Maka diperoleh sampel sebanyak 93 orang dari total 1415 orang tua siswa. Dari jumlah sampel itu, diproposikan kepada jumlah orang tua siswa di SMAN 1 Sungai Penuh (52 orang) dan MAN 1 Sungai Penuh (41 orang).

\section{Teknik Analisis}

Analisis data menggunakan analisis deskriptif dengan menggunakan presentase dengan rumus (Sudijono, 2010).

$$
P=\frac{F}{N} \times 100 \%
$$

Data yang telah diperoleh diuji normalitasnya dengan menggunakan SPSS 16.0. Data deskriptif juga diolah dengan bantuan perangkat lunak Microsoft Excel dan SPSS 16.0. penskoran dilakukan dengan kententuan Saifudin Anwar (2005) dengan kategori "Sangat Baik", "Baik", "Cukup Baik", "Kurang Baik", dan "Sangat Kurang Baik".

\section{HASIL PENELITIAN DAN PEMBAHASAN$$
\text { Hasil Penelitian }
$$ \\ Berdasarkan hasil penelitian, ditemukan bahwa persepsi orang tua}


siswa tentang geografi sebagai mata pelajaran di SMA/MA Negeri di Kota Sungai Penuh yang menyatakan pada kategori sangat baik dengan persentase $7,53 \%$, pada kategori baik dengan persentase $20,43 \%$, pada kategori cukup baik dengan persentase $35,48 \%$, pada kategori kurang baik dengan persentase $34,41 \%$ dan pada kategori sangat kurang baik dengan ersentase $2,15 \%$.

Dalam penelitian ini, peneliti meneliti persepsi orang tua siswa tentang geografi sebagai mata pelajaran di SMA/MA Negeri di Kota Sungai Penuh di ukur berdasarkan empat tujuan penelitian, antara lain sebagai berikut:

1. Persepsi orang tua siswa tentang peran ilmu geografi dalam suatu profesi tergolong "Kurang baik", yaitu dengan persentase sebesar $38,71 \%$.

2. Persepsi orang tua siswa tentang peran mata pelajaran geografi dalam membentuk sikap peduli lingkungan tergolong "Baik" dengan prsentase $32,26 \%$.

3. Persepsi orang tua siswa tentang peran ilmu geografi dalam pemecahan masalah global tergolong "Cukup baik" dengan persentase sebesar $49,46 \%$.

4. Persepsi orang tua siswa tentang pembelajaran geografi tergolong "Cukup baik" dengan persentase $33,33 \%$.

\section{Pembahasan}

Penelitian ini meneliti bagaimana persepsi orang tua siswa tentang geografi sebagai mata pelajaran di SMA dan MA Negeri di Kota Sungai Penuh. Penelitian ini dilakukan karena dari pengamatan peneliti dan dari beberapa sumber yang ada, pembelajaran geografi masih kurang maksimal, lulusan geografi belum memadai, dan masyarakat cendrung tidak begitu paham mengenai apa itu geografi. jadi, untuk melihat bagaimana persepsi orang tua tersebut, peneliti melakukan penelitian ini dengan menggunakan empat indikator, antara lain:

1. Persepsi Orang Tua Siswa tentang Peran Ilmu Geografi dalam Suatu Profesi

Dalam peran ilmu geografi sebagai suatu profesi, orang tua mempersepsikan peran ilmu geografi dalam suatu profesi kurang baik. Hal ini menunjukkan persepsi orang tua siswa masih belum sesuai dengan persepsi yang diharapkan. Dengan kurang baiknya persepsi orang tua tentang peran ilmu geografi dalam suatu profesi, orang tua siswa bisa tidak percaya untuk memasukkan anaknya di jurusan geografi di perguruan tinggi. Orang tua siswa juga tidak yakin dengan profesi yang akan digeluti oleh anaknya jika masuk di jurusan geografi, karena persepsi yang masih kurang baik.

2. Persepsi Orang Tua Siswa tentang Peran Ilmu Geografi dalam Membentuk Sikap Peduli Lingkungan.

Persepsi orang tua siswa tentang peran ilmu geografi dalam membentuk sikap peduli lingkungan siswa tergolong baik dan cukup baik dengan seimbang atau sama, yaitu sama-sama 32,26\%. Hal ini menunjukkan persepsi yang positif dari orang tua terhadap peran ilmu geografi dalam membentuk sikap peduli lingkungan. Hal ini juga tercermin dalam kurikulum geografi baik KTSP atau Kurikulum 2013 yang mana mata pelajaran geografi memuat materi mengenai lingkungan hidup. Dalam kurikulum, tidak hanya mengedepankan kognitif, melainkan 
juga mengedepankan sikap yang terbentuk dalam proses pembelajaran, salah satunya sikap peduli lingkungan.

3. Persepsi Orang Tua Siswa tentang Peran Ilmu Geografi dalam Pemecahan Masalah Global

Berdasarkan hasil penelitian ini, persepsi orang tua siswa tentang peran ilmu geogafi dalam pemecahan masalah global tergolong cukup baik. Hal ini menunjukkan pengetahuan orang tua siswa cukup baik mengenai mata pelajaran geografi. Karena, geografi adalah ilmu yang mempelajari masalah-masalah global dalam kurikulumnya, mulai dari masalah fisik, sosial dan politik secara global. Persepsi yang cukup baik juga menunjukkan bahwa persepsi orang tua siswa tidak buru tentang peran ilmu geografi dalam pemecahan masalah global.

4. Persepsi Orang tua Siswa tentang Pembelajaran Geografi di Sekolah Berdasarkan hasil penelitian, persepsi orang tua siswa tentang pembelajaran geografi di sekolah tergolong cukup baik. Persepsi orang tua siswa tentang pembelajaran geografi ini didasarkan atas lima sub indikator, yaitu pelaksanaa, bahan ajar, metode dan strategi, media, dan evaluasi. Persepsi orang tua tergolong cukup baik berarti orang tua siswa cukup paham mengenai pembelajaran geografi di sekolah dan bagaimana pembelajaran seharusnya di sekolah.

Berdasarkan hasil penelitian, persepsi orang tua siswa tentang pembelajaran geografi di sekolah tergolong "cukup baik". Persepsi orang tua siswa tentang pembelajaran geografi ini didasarkan atas lima sub indikator, yaitu pelaksanaa, bahan ajar, metode dan strategi, media, dan evaluasi. Persepsi orang tua tergolong cukup baik berarti orang tua siswa cukup paham mengenai pembelajaran geografi di sekolah dan bagaimana pembelajaran seharusnya di sekolah.

Persepsi yang positif terhadap mata pelajaran apapun penting untuk prestasi siswa dan juga ketertarikan mereka pada kehiudpannya di masa depan (Verma dan Deshpande, 2015). Jika pembelajaran geografi berlangsung dengan baik di sekolah, tujuan-tujuan belajar tercapai, maka persepsi orang tua akan semakin baik terhadap pembelajaran gegorafi. Persepsi orang tua siswa yang masih tergolong cukup baik ini berarti guru geografi, sekolah, dan instatnsi yang terkait harus dapat mengembangkan pembelajaran geografi dengan lebih baik lagi untuk mencapai persepsi yang sangat baik.

\section{PENUTUP \\ Kesimpulan}

Berdasarkan penelitian mengenai Persepsi Orang Tua Siswa terhadap Geografi Sebagai Mata Pelajaran di SMA dan MA Negeri di Kota Sungai Penuh, yang menyatakan pada kategori sangat baik dengan persentase $7,53 \%$, pada kategori baik dengan persentase $20,43 \%$, pada kategori cukup baik dengan persentase $35,48 \%$, pada kategori kurang baik dengan persentase $34,41 \%$ dan pada kategori sangat kurang baik dengan persentase 2,15\%. Jadi, dapat disimpulkan Persepsi Orang Tua Siswa terhadap Geografi Sebagai Mata Pelajaran di SMA dan MA Negeri di Kota Sungai Penuh tergolong cukup baik.

\section{Saran}

Berdasarkan kesimpulan di atas, peneliti memberikan beberapa saran bagi pembelajarn geografi di tingkat SMA dan MA, yaitu: 
1. Bagi peneliti selanjutnya, hendaknya menggunakan faktrofaktor persepsi yang berbeda sehingga persepsi orang tua tentang geografi sebagai mata pelajaran dapat teridentifikasi secara luas.

2. Bagi guru dan sekolah untuk dapat meningkatkan kualitas pembelajaran geografi di sekolah, supaya pemahaman akan pentingnya pembelajaran geografi dapat dipahami oleh siswa dan masyarakat luas.

\section{DAFTAR PUSTAKA}

Ali, Mohamad. 2006. Ilmu Pendidikan. Bandung: Pedagogiana Press.

Anwar, Saifudin. 2005. Teori dan Pengukuran. Yogyakarta: Pustaka Pelajar.

Departemen Pendidikan Nasional, 2008. Kamus Bahasa Indonesia.

Kementerian Pendidikan dan Kebudayaan. 2016. Silabus Mata Pelajaran Geografi Sekolah Menengah Atas/Madrasah Aliyah. Jakarta.

Peraturan Menteri Pendidikan dan Kebudayaan, No. 58 Tahun 2014, Tentang Kurikulum 2013 SMP/MTs.

Rini, Yohana Susetyo. 2014. "Komunikasi Orangtua-Anak dalam Pengambilan Keputusan Pendidikan". Jurnal Interaksi Nomor 02, Juli 2014.

Seminar dan Lokakarya Geografi, Semarang, 1988.
Setiyana. 2013. Persepsi Orang Tua / Wali Siswa Terhadap MataPelajaran Pendidikan Jasmani Olahraga Dan Kesehatan Di Sekolah Dasar Negeri Harjobinangun, Kecamatan Grabag, Kabupaten Purworejo. Skripsi. Yogyakarta: FIK UNY

Sudijono, Anas. 2010. Pengantar Statistik Pendidikan. Jakarta : Raja Grafindo Persada.

Sujarweni, Wiratna. 2014. SPSS untuk Penelitian. Yogyakarta: Pustaka Baru

Usman, Husaini dan Akbar, Purnomo Setiady. 2011. Pengantar Statistika, Edisi Kedua. Jakarta: Bumi Aksara.

Verma, Mukesh dan Deshpate, Sarita (2015) "Perception of Students about Geography in FNU: A case study". First International Conference on Theory and practice, ICTP, Lautoka: Fiji National University.

Walgito, Bimo. 2003. Pengantar Psikologi Umum. Yogyakarta: Andi Offset. 
